\title{
Aspects of correlation between the surface analysis and heavy metal content in temporary teeth from areas with various pollution levels of Romania
}

\author{
M. Prodana ${ }^{1}$, A. Meghea ${ }^{1}$, G. Stanciu ${ }^{1}$, R. Hristu ${ }^{1}$ and I. Demetrescu ${ }^{1}$
}

\begin{abstract}
The paper aims the evaluation and discussion of behavior of natural temporary teeth from groups of children living in regions with various pollution areas regarding the level of heavy metals. The small amounts of very aggressive metals such as $\mathrm{Cd}$ and $\mathrm{Pb}$ detected in the groups of teeth by using an ELAN DRC-e induced plasma coupled spectrophotometer (ICP-MS) have been correlated with surface aspects discussed based on confocal microscopy and wettability. The correlations sustain the idea that the teeth from high pollution areas exhibit higher roughness and many holes, being in fact more degraded. A statistical treatment according to ANOVA test completed this study.
\end{abstract}

Index Terms - temporary teeth, heavy metals, surface analysis, ICP-MS, confocal microscopy.

\section{INTRODUCTION}

In the last decade, based on the heavy metal levels present in both tooth compartments, enamel and dentine, which appear as permanent and chronological indicators for the nutrition state and also for the individual exposure to the environmental factors, many studies have been devoted to correlation between oral health, composition and surface aspects of teeth from various regions of the world, with different potential risks to the impact of heavy metals [1-3]. A series of papers contained arguments for relation between heavy metal content and the number of carries of patients, but according to literature data $[1,4,5]$ it is difficult to have a clear conclusion in this moment [7-9]. First of all the number of carries as an expression of oral health could be the result of many other social factors, and despite the fact that the environment quality is a part of quality of life, it is very difficult to be sure that the teeth are collected from a target group with similar life conditions. It is desirable to build such target groups and to complete the number of experiments both at enamel and at dentine level.

The paper aims at evaluating and discussion on behavior of natural temporary teeth from groups of children living in three regions with various pollution areas regarding the level of heavy metals, sampled from a high risk region in case of

M. Prodana, A. Meghea, G. Stanciu, R. Hristu and I. Demetrescu :University Politehnica Bucharest, Romania group 1, medium risk region for group 2, to less risk region in case of group 3. In all these cases the contents of very aggressive metals, such as $\mathrm{Cd}$ and $\mathrm{Pb}$, were in rather small amounts and other types of elemental analyses, except induced plasma coupled spectrophotometer (ICP-MS), were not efficient, only this technique permitting to put in evidence such trace metals.

Adequate methods to investigate surface properties modifications of teeth based on confocal microscopy and wettability are also used and discussed in order to formulate the main goals of this work. The wettability phenomenon is described in the framework of classic approach based of fundamental Young equation, dealing with the thermodynamic equilibrium of the interfacial energies which can indicate the hydrophilic-hydrophobic balance in terms of contact angles. The microscopy analysis was performed at various tooth zones including enamel, dentine, channel and root, and for each sample optical section images have been registered. The results obtained on both techniques are discussed in connection with heavy metal content in nearby region in order to evaluate the possible pollution impact on degradation degree of children teeth.

\section{EXPERIMENTAL PART}

\section{A. Tooth collection and sample elaboration}

The methodology of this study started with formation of three target groups of children living in areas with various risk impacts regarding heavy metals. As a reference not polluted area, a small village in mountain clean region, Patarlagele, has been selected, while as an area with environmental risk, an industrial zone around Bucharest has been chosen. This last part was divided in two sections, one of them being located around an old car batteries factory, with still active activities regarding pollution, and the other site with a medium risk of heavy metals at this moment, this region being disaffected at present. The source of lead may considerably vary. It may emanate either from areas with industries without efficient treatment of waste water, or from paints, plumbing, food and gasoline. Despite great efforts made to prohibit the use of lead, children are still exposed 
due to residual lead contamination in soil. However, the identification of selected regions for target group formation in areas with various pollution levels was based on reports provided by National Environmental Agency. The characteristics regarding age and sex of selected children from reference and target groups were supposed to be similar. Regarding the sample preparation, the extracted teeth were thoroughly washed under tap water to remove saliva, blood, and tissue debris. The teeth were cleaned and polished with silicon carbide slurry.

\section{B. Teeth characterization}

For heavy metal level determination an ELAN DRC-e induced plasma coupled spectrophotometer was used (ICP-MS) and samples were taken from two different compartments: enamel and dentin. All samples (typically: $0.1-1.2 \mathrm{mg}$ ) were digested in $100 \mathrm{~mL}$ concentrated nitric acid (ULTRAPURE, Fa. Merck). Acid digestion was performed in a well determined volume of $\mathrm{HNO}_{3} 65 \%$; after digestion, the samples were diluted 100 times and liquid fractions were analyzed.

Wettability has been quantified by using a Contact Angle Meter - KSV Instruments CAM 100, and the surface hydrophilicity of samples was studied by measuring static contact angle with sessile drop of distilled water deposited on the sample surface. Wetting was evaluated by measuring the contact angle formed between the liquid drop and solid surface. The volume of the liquid was kept constant $(10 \mu \mathrm{L})$ all over the contact angle measurements of the different samples and the image of liquid drop was recorded by video camera. Each contact angle value is the average of minimum 10 measurements. The investigation was carried out with an acurrancy of $\pm 1^{0}$ at a temperature of $25^{\circ} \mathrm{C}$.

Regarding microscopic analysis, the samples were investigated with a confocal microscope Leica TCS SP1, using an objective $10 \mathrm{X}$ with a numerical aperture $\mathrm{NA}=0.3$, permitting a maximum scanning window $1 \mathrm{~mm} \times 1 \mathrm{~mm}$. Appling a supplementary zoom this window is reduced. The laser used is with He-Ne system and wave length of $633 \mathrm{~nm}$. For each dentine sample specific optical sections, topograhy and $3 \mathrm{D}$ images have been obtained. Based on topography and histograms registered, the roughness (RMS) of the samples has been also evaluated. The last two data are the result of soft ware superposition of optical sections of samples. The images dimensions are 1024 x 1024 pixels.

\section{Statistic analysis}

In order to establish some quantitative correlations between the heavy metal content in temporary tooth and their wettability and carious activity (dmtfs) a univariant statistical method of analysis, simple ANOVA, has been used for the samples taken from the reference area. For the carious activity the static unite of dental surface has been considered. The ANOVA technique can be used when there is only one independent variable in more than two steps, respectively of target groups, and only one dependent variable. It allows a simultaneous comparison of three or many groups and a significant correlation is obtained when for a linear regression the level of slope (p- factor) is less than 0.05 but different from zero.

\section{RESUlTS AND DisCUSSION}

Based on human and animal studies, a number of 5 types of elements have been proposed in the literature, depending on their cariogenicity. $[10,11]$ This proposal which summarized the cariogenic effect of many of the minerals included in the cariostatic group some elements like $\mathrm{F}$ and $\mathrm{P}$, and placed various heavy metals, such as $\mathrm{Mn}, \mathrm{Sn}$ and $\mathrm{Zn}$, in the range of middle cariostatic. Other elements like $\mathrm{Al}, \mathrm{Ni}$ and $\mathrm{Fe}$ are treated as caries inert, while some other aggressive heavy metals, like $\mathrm{Cd}$ and $\mathrm{Pb}$ are defined as caries promoting.

Our previous research with the ICP-MS experiments identified small amounts of a large number of heavy metals with various effects on teeth [12-14], for a series of samples collected from areas with different pollution levels, and specific correlations between sex of children, type of tooth and the heavy metal content were proposed. [15]

\section{A. Biostatistic analysis of samples from reference area}

Before presenting the analysis of heavy metal content on temporary teeth state, a statistic analysis of the parameters specific to samples taken from the reference area has been performed, in order to establish the possible correlation degree among different variables. The data collected for biostatistic analysis are presented in the table 1.

TABLE 1. DATA USED FOR BIOSTATISTIC ANALYSIS

\begin{tabular}{|c|c|c|c|c|c|c|c|}
\hline Sample & Age & $\begin{array}{l}\text { Contact } \\
\text { angle }\end{array}$ & $\begin{array}{c}\mathrm{Cu} \\
\mathrm{ppm}\end{array}$ & $\begin{array}{c}\mathrm{Cd} \\
\mathrm{ppm}\end{array}$ & $\begin{array}{c}\mathrm{Pb} \\
\mathrm{ppm}\end{array}$ & $\begin{array}{c}\mathrm{Hg} \\
\mathrm{ppm}\end{array}$ & dmfs \\
\hline 1 & 7 & 50.52 & 0.92 & 0.08 & 0.24 & 0.34 & 7 \\
\hline 2 & 6 & 24.7 & 0.56 & 0.07 & 0.21 & 0.29 & 15 \\
\hline 3 & 9 & 36.69 & 0.47 & 0.06 & 0.2 & 0.26 & 7 \\
\hline 4 & 6 & 50.34 & 0.31 & 0.06 & 0.18 & 0.24 & 15 \\
\hline 5 & 5 & 89.17 & 0.69 & 0.1 & 0.08 & 0.22 & 4 \\
\hline 6 & 6 & 61.04 & 0.52 & 0.08 & 0.04 & 0.13 & 9 \\
\hline 7 & 6 & 69.14 & 1.23 & 1.85 & 0.78 & 0.76 & 0 \\
\hline 8 & 5 & 94.92 & 1.04 & 1.66 & 0.54 & 0.63 & 1 \\
\hline 9 & 5 & 60.92 & 1 & 0.78 & 0.43 & 0.51 & 17 \\
\hline 10 & 6 & 93.54 & 0.85 & 0.54 & 0.36 & 0.46 & 12 \\
\hline 11 & 5 & 79.14 & 0.54 & 0.06 & 0.14 & 0.28 & 2 \\
\hline 12 & 11 & 82.78 & 0.36 & 0.08 & 0.17 & 0.09 & 5 \\
\hline 13 & 9 & 78.21 & 0.39 & 0.4 & 0.66 & 0.04 & 15 \\
\hline 14 & 6 & 44.03 & 0.08 & 0.2 & 0.51 & 0.02 & 0 \\
\hline 15 & 6 & 103.9 & 0.32 & 0.02 & 0.71 & 0.7 & 6 \\
\hline 16 & 7 & 54.28 & 0.13 & 0.01 & 0.11 & 0.23 & 17 \\
\hline
\end{tabular}

By applying simple ANOVA technique and linear regression analysis, the correlation parameters are shown in the table 2 .

TABLE 2. CORRELATION OF BIOSTATISTIC PARAMETERS

\begin{tabular}{|c|c|c|}
\hline Correlated parameters & R-coeff. & ANOVA-p \\
\hline$(\mathrm{Cu}+\mathrm{Cd}) \%$, & 0.820 & 0.00017 \\
\hline$(\mathrm{Pb}+\mathrm{Hg}) \%$ & 0.550 & 0.03192 \\
\hline Age & 0.0980 & 0.72000 \\
\hline Contact angle & 0.780 & 0.00002 \\
\hline
\end{tabular}


In the above correlation of biostatistics parameters, the $\mathrm{R}$ coefficient is the correlation degree $[16,17]$.

Three types of correlation levels can be obtained when the carious activity (dmtfs) has been correlated with different independent variables.

Referring to the heavy metal content, two situations are evidenced: a very good correlation between $\mathrm{dmtfs}$ and the content in $(\mathrm{Cu}+\mathrm{Cd}) \%$, with correlation coefficient $\mathrm{R}=0.82$, and the slope $\mathrm{p}=0.00017$, that is much below 0.05 , thus confirming the high degree of this correlation.

A similar relation followed with $(\mathrm{Pb}+\mathrm{Hg}) \%$ content reveals a medium correlation degree $(\mathrm{R}=0.55)$, supported also by the value of $\mathrm{p}=0.03$, higher but still below the limit correlation value of 0.05 . No correlation could be established between the carious activity and the age of target group members.

However, there is a quite good correlation of carious activity and the surface characteristics of tooth, here represented by contact angle values, as is reflected in the last line of data in the table 2. This conclusion on biostatistic analysis justifies the study further performed in order to establish the possible correlation between pollution degree of various investigated areas reported by heavy metal content and the state of temporary tooth of children living in these polluted sites.

\section{B. Correlation of surface analysis and heavy metal content}

Starting form the idea that the amount of heavy metals released from teeth is greater in case of dentine, the present study is mainly devoted to analysis of correlation between $\mathrm{Pb}$ and $\mathrm{Cd}$ contents from dentine and surface aspects presented in table 3 .

TABLE 3. HEAVY METAL CONTENT AND SURFACE CHARACTERISTICS OF

\begin{tabular}{|c|c|c|c|c|c|c|}
\hline \multicolumn{7}{|c|}{ SAMPLES } \\
\hline Sample & $\begin{array}{c}\text { Tooth } \\
\text { type }\end{array}$ & RMS & $\begin{array}{c}\mathrm{Pb} \\
\mathrm{ppm}\end{array}$ & $\begin{array}{c}\mathrm{Cd} \\
\mathrm{ppm}\end{array}$ & $\begin{array}{c}\text { Contact } \\
\text { angle }\end{array}$ & Pollution area \\
\hline $\mathrm{H} 1$ & molar & $\begin{array}{c}29.6 \\
5\end{array}$ & 14,5 & 26,9 & 70,53 & $\begin{array}{c}\text { Bucharest } \\
\text { (high pollution } \\
\text { risk) }\end{array}$ \\
\hline $\mathrm{H} 2$ & incisor & $\begin{array}{c}28.6 \\
1\end{array}$ & 4,6 & 30,2 & 69,35 & $\begin{array}{c}\text { Bucharest } \\
\text { (high pollution } \\
\text { risk) }\end{array}$ \\
\hline H3 & canine & $\begin{array}{c}30.1 \\
7\end{array}$ & 2,1 & 20,1 & 49,67 & $\begin{array}{c}\text { Bucharest } \\
\text { (high pollution } \\
\text { risk) }\end{array}$ \\
\hline M1 & molar & $\begin{array}{c}26.5 \\
2\end{array}$ & 10,2 & 23,2 & 62,87 & $\begin{array}{c}\begin{array}{c}\text { Bucharest } \\
\text { (medium }\end{array} \\
\text { pollution risk) }\end{array}$ \\
\hline M2 & incisor & $\begin{array}{c}26.4 \\
5\end{array}$ & 19,8 & 12,7 & 50,55 & $\begin{array}{c}\text { Bucharest } \\
\text { (medium } \\
\text { pollution risk) }\end{array}$ \\
\hline M3 & canine & $\begin{array}{c}27.8 \\
9\end{array}$ & 3,6 & 7,2 & 36,48 & $\begin{array}{c}\text { Bucharest } \\
\text { (medium } \\
\text { pollution risk) }\end{array}$ \\
\hline R1 & canine & $\begin{array}{c}27.7 \\
6\end{array}$ & 0,2 & 9,8 & 34,43 & $\begin{array}{c}\text { Moreni (low } \\
\text { pollution risk) }\end{array}$ \\
\hline
\end{tabular}

In table 3 the experiments has shown that $\mathrm{Pb}$, even in very low levels, may be found in the dentine of primary teeth from children exposed or not exposed to environmental risk to lead.

As referring to surface aspects, it is well known from literature that the wetting of a surface by liquid is affected by roughness of this surface. On very rough surfaces, contact angles are larger than on chemically smooth surfaces. Therefore, the hydrophilic surfaces become more hydrophilic and those hydrophobic become more hydrophobic as a result of a process where the liquid fills the space existing on the surface among protrusions.

As can be seen from table 3, all the contact angle values are in hydrophilic domain $(<90)$; however, the teeth collected from high pollution risk areas give samples with less hydrophilic character compared to the other two regions, thus being in agreement with previous results. [11,13] As it is expected, a clear correlation can be made between the total heavy metals content $(\mathrm{Pb}+\mathrm{Cd})$ and wettability of teeth dentine, their surfaces being smoother for teeth sampled from low or medium polluted areas. It follows that the degradation degree of teeth as a result of heavy metal impact can be ordered after the increasing of dentine wettability in the series: molar $>$ incisor $>$ canine.

One of the most appropriate non-invasive high resolution techniques able to provide valuable information on the quality of the tough dental tissues, particularly on their defects (cracks and holes) is confocal microscopy. For instance, in figure 1, the optical section is illustrated for a sample collected from a high polluted area, the structure of the dental channel being evidenced. For the same sample, in the figure 2, the topography of the investigated zone and its $3 \mathrm{D}$ profile are also illustrated.

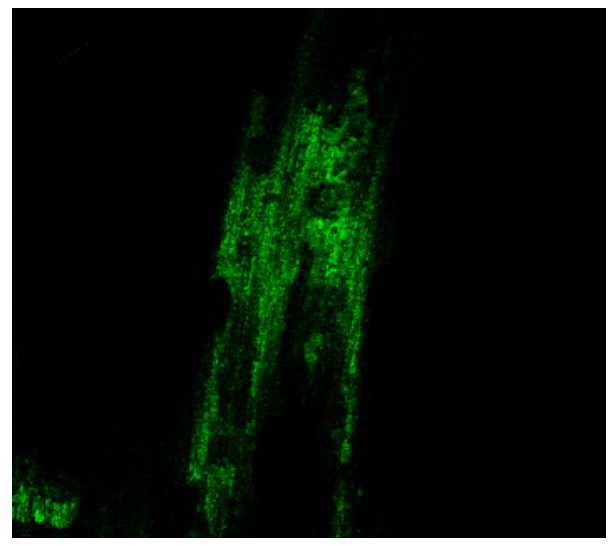

Fig. 1. Optical sections in the sample B10-71 

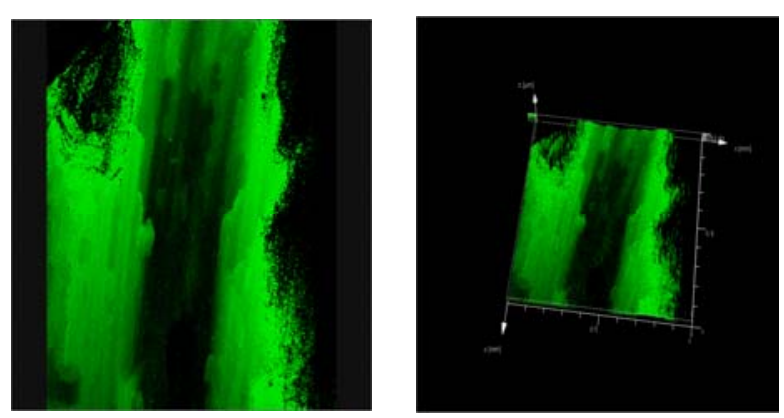

Fig. 2. Topography of the sample B10-71 (left) and its 3D image (right)

This is also an appropriate technique to evaluate the difference in enamel thickness near the root and at the apex of tooth, as it is illustrated in the figure 3 .
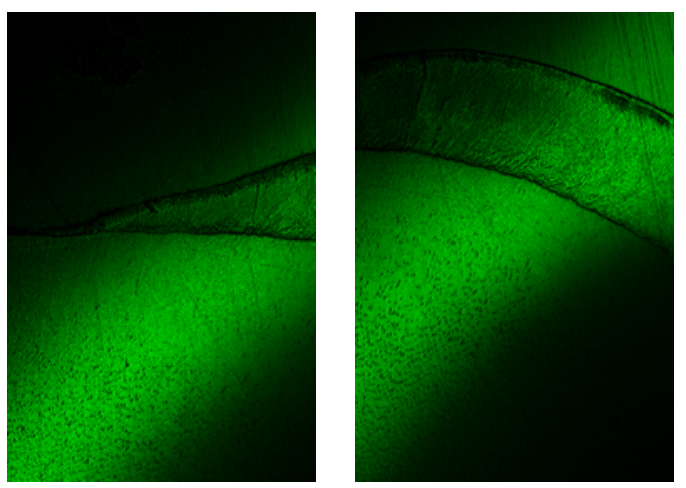

Fig.3. Optical section of teeth: dentine and enamel near the root (left) and near the apex (right)

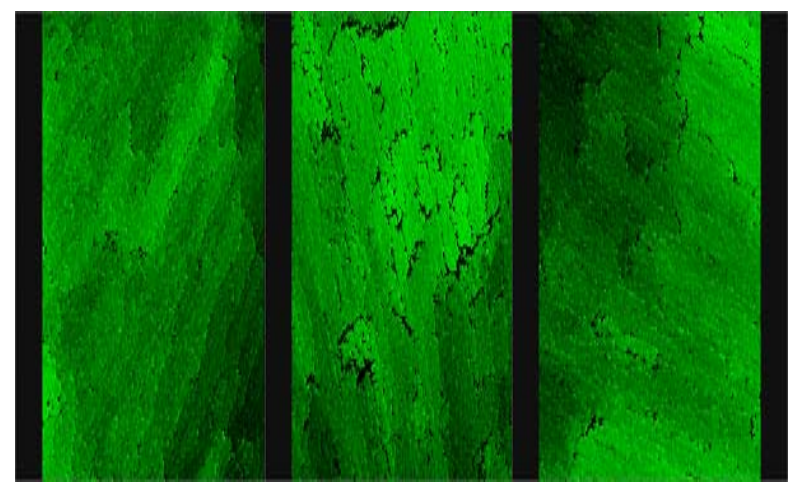

Fig.4. Topographies for the samples B6-84, B10-71, and B11-81, respectively
A comparison of the topography images obtained for various types of teeth collected from high, and respectively, medium polluted areas is shown in figures 4 and 6. Correspondingly, these images are accompanied by their histograms presented in figures 4 and 6 . Based on these microscopy data the roughness (RMS) of the samples has been calculated, as it is presented in the table 1.

The analysis of these data reveals that the topographies provided by the samples from high polluted area (Fig.4) exhibit a higher roughness than those from medium polluted area (Fig. 6), and much more cracks and holes are evidenced. At the same time, a similar evolution in roughness can be noticed for both groups referring to the type of teeth: canine $>$ molar $>$ incisor.
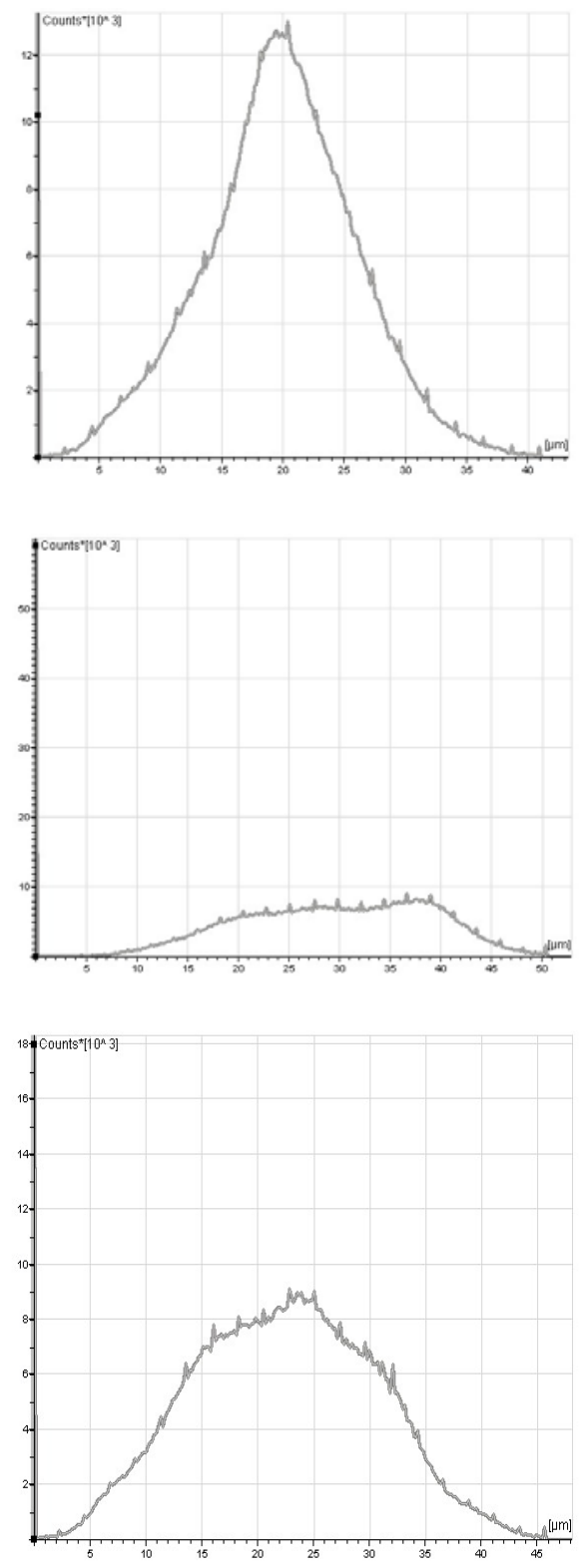

Fig. 5. Topography histograms of samples from fig. 4 


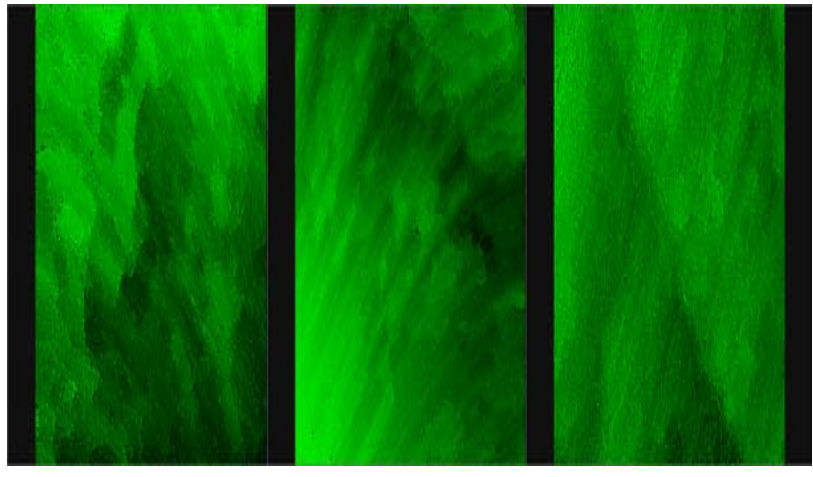

Fig. 6 Topographies for the samples F2-75, F4-65, and F10-51, respectively
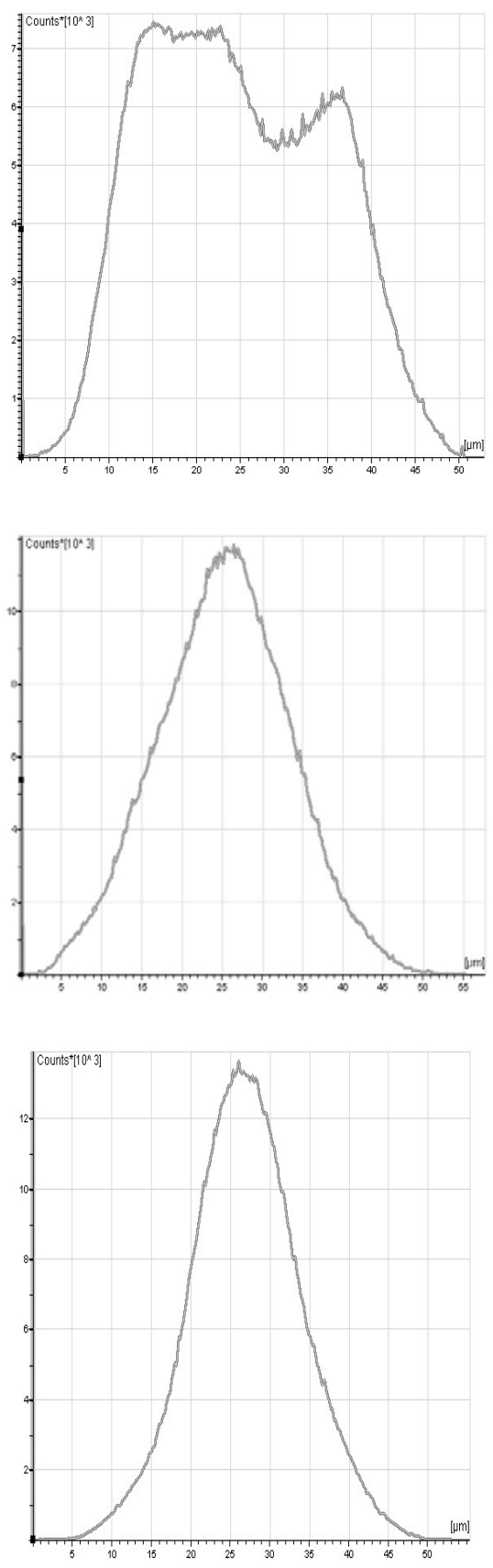

Fig. 7. Histograms of topographies from fig. 6
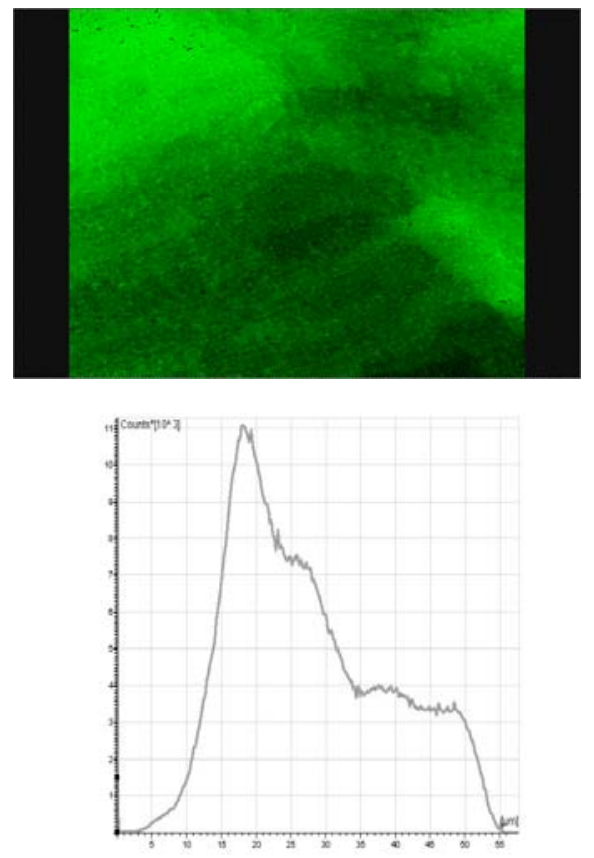

Fig. 8. Topography and histogram of the sample M15-55

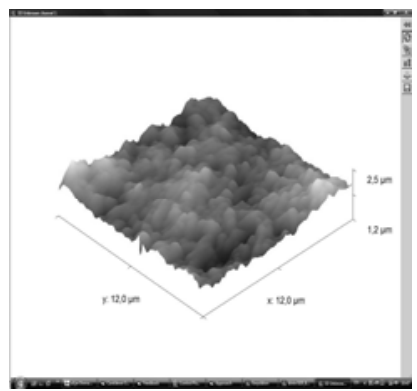

(a)

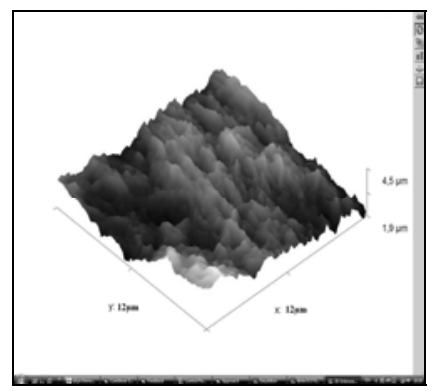

(b)
Fig.9 AFM picture of teeth from: (a) - high polluted area and (b) - low polluted area

The topography and histogram of reference sample taken from low pollution risk area are presented in the figure 8 . However, it can be mentioned that the roughness values are not so relevant to be directly correlated with potential environmental impact caused by heavy metal content, all the RMS values ranging within a quite narrow interval (26-30). Topography analysis was completed with AFM experiments.

As can be seen in AFM images presented in figures 9, such determinations sustain the same idea on different aspects of teeth sampled from areas with various pollution levels. In this respect, wettability of sample surfaces measured by contact angle values are much more relevant in reflecting this influence, the data ranging on a wider interval (34-70). 


\section{CONCLUSION}

The impact of heavy metal content in high polluted area on degradation of temporary teeth can be correlated with surface aspects of their dentine, particularly with surface wettability quantified by contact angle measurements. It was established that the degradation degree is also dependent on the nature of teeth in the series: molar $>$ incisor $>$ canine. Confocal microscopy is a valuable non-invasive technique in detecting tooth defects, holes and cracks, but the roughness values estimated from the histograms are not so relevant for correlation with heavy metal impact in high polluted area.

\section{ACKNOWLEDGEMENTS}

The authors thank to National Romanian Program PN2, 41-005/207 for supporting this research work.

\section{REFERENCES}

[1] P. Malara, J. Kwapulinski, B. Malara, "Do the levels of selected metals differ significantly between the roots of carious and non-carious teeth?" in Science of the Total Environment, 369, 2006, pp .59-68.

[2] I. Demetrescu, I.D. Iordachescu, D. Ionita, S. Manea, "Surface analysis and cell biology technique in understanding degradation of natural temporary teeth collected from area with high pollution" in. Key Engineering Materials, 396-398, , 2009, pp. 35-38.

[3] R. Cleymaet, P. Bottenberg, D. Slop, R. Clara and D. Coomans, "Study of lead and cadmium content of surface enamel of school children from an industrial area in Belgium" in Community Dent Oral Epidemiol, , 19, 199, pp. 107-111.

[4] N. Youravong, V. Chongsuvivatwong, A.F. Geater, G. Dahlen and R. Teanpaisan, "Lead associated caries development in children living in a lead contaminated area, Thailand"in Sci Total Environ,, 361, 2006, pp. 88-96.

[5] V.Verbic, J Stuper, AR Byrne, "Trace element content of primary and permanent tooth enamel". In Caries Res 21, 1987,:pp. 37-39

[6] N.D. Shashikiran, V.V. Subba Reddy, M.C. Hiremath, "Estimation of trace elements in sound and carious enamel of primary and permanent teeth by atomic absorption spectrophotometry: An in vitro study." in Indian J Dent Res, 18, 2007, pp.157-62.

[7] A. Fischer, J. Kwapuliński, D. Wiechuła, T. Fischer, M. Loska, The occurrence of copper in deciduous teeth of girls and boys living in Upper Silesian Industry Region (Southern Poland). Science of the Total Environment, 2008, 389, 2-3,pp. 315-319.

[8] A. Helle, K. Haavikko, "Macro- and micromineral levels in deciduous teeth from different geographical areas correlated with caries prevalence" in. Proc. Finn Dent.Soc, 73, , 1977, pp. 87-98.

[9] M. Riyat, D.C. Sharma, "Analysis of 35 Inorganic Elements in Teeth in Relation to Caries Formation" in. D.C. Biological Trace Element Research; 129 (1), , 2009, pp.126-129.

[10] K.Bercovitz, D. Laufer, "Carious teeth as indicators to lead exposure"in Bull Environ Contam Toxicol, 50, 1993, pp.724-729.

[11] J.M. Navia, "Prevention of dental caries: Agents which increase tooth resistance to dental caries" in. Int Dent J; 22, 1972, pp.427-40.

[12] I. Demetrescu, R. Luca, D. Ionita, D. Bojin, "ICP/MS in evaluation heavy metal influence on the behavior of natural temporary teeth" in . Key Engineering Materials,, 396-398, 2009, pp. 175-178.

[13] M. Prodana, D. Ionita , G. Stanciu, I. Demetrescu, "Surface topography and balance hydrophyl hydrophob of temporary teeth from area with heavy metal risk" in. Proceedings of Biomed 2004 Conference, Bucharest.

[14] M. Prodana, R. Luca, F. Miculescu, D. Bojin, "A new approach in evaluation surface properties of natural temporary teeth from high polluted area" in. Key Engineering Materials, 396-398, 2009, pp. 21-24.

[15] I. Demetrescu, R. Luca, D. Ionita, M. Prodana, "Evaluating environmental impact factors as heavy metals on behavior of temporary teeth" in. Molecular Crystals \& Liquid Crystals, in press.
[16] S.Sawilowsky, "Review of the rank transform in designed experiments" in. Perceptual and Motor Skills, 90, 2000, pp.489-497

[17] J.Zar, "Biostatistical analysis $4^{\text {th }}$ ed., N.J. Prentice Hall. 